\title{
Investigation on on-line monitoring method for lubricating oil deterioration
}

\author{
Ying Du, Tonghai $\mathrm{Wu}^{*}$, Longxin Wang, and Renjie Gong \\ Key Laboratory of Education Ministry for Modern Design and Rotor-Bearing System, Xi'an Jiaotong University, \\ Xi'an 710049, PR China
}

Received: 29 September 2015 / Accepted: 16 June 2017

\begin{abstract}
Lubricating oil deterioration in operating machinery is a complicated and dynamic process with combined effects of working conditions, contaminations and wear conditions, which makes the process unpredictable in the whole life-span cycle, and the deteriorated lubricating oil may increase wear rate and cause severe wear afterwards. On-line monitoring provides the only solution to evaluate the overall variation of lubricating oil conditions by supplying real-time data. Focusing on this issue, this paper presents an investigation on the process of lubricating oil deterioration with an on-line multi-object monitoring system. Three monitoring indexes, including viscosity, permittivity and wear debris, were adopted. A four-ball tester was applied to produce accelerated oil degradation, and was monitored with the on-line monitoring system. In addition, off-line oil analysis was also adopted for verification. The main results demonstrate that the selected three indexes can reflect the aging process of lubricating oil from different aspects quantitatively. The variation rate of viscosity can represent different working conditions of the tribo-pairs, the permittivity indirectly represents the oxidation degree of lubricating oil, and the wear characteristics indicates three wear stages of tribo-pairs including run-in, normal wear and severe wear, which meets the typical "Bathtub Curve" very well.
\end{abstract}

Keywords: lubricating oil / oil deterioration / on-line monitoring / oil analysis / four-ball test

\section{Introduction}

Lubricating oil, which is composed of base oil and varieties of additives and contains significant tribological information on an operational process, plays a vital role in the full life-span performances of the machine [1]. Excepting for lubricating the tribo-pairs, lubricating oil can scavenge wear particles, remove heat from friction surfaces [2], etc. Due to oxidation and thermal stresses in working conditions, physical and chemical properties of lubricating oil will degrade and eventually cause the increase of wear rate, which begins with additives depletion followed by oxidation of the base oil [3-5]. Therefore, changing oil on a proper time becomes very important, where late replacement of the oil will lead to the failure of the equipment, but premature replacement will be costly for consumers. In consequence, it is imperative to monitor the deterioration of lubricating oil, which could reveal the deterioration of tribo-system [6] and make a quick and accurate judgment about oil change and maintenance.

* e-mail: wt-h@163.com
According to the previous attempt of lubricant analysis in machine condition monitoring, off-line approach is proved to be useful but limited in industry [7]. Oil samples are normally collected from the equipment and delivered to the laboratories for analysis before a report can be achieved. A determined action, like specific maintenance, can only be made after finishing oil analysis somewhere else. Correspondingly, it becomes a difficult work to relate the analysis result to current machine status because of the time lag [8]. Therefore, on-line oil monitoring is proposed and regarded as a more suitable method for condition monitoring of machine health [9]. For this purpose, various on-line methods based on physical and chemical principles are proposed to evaluate oil condition with numerous indicators, such as viscosity, permittivity, temperature, water content and index of specific contamination [3].

Widely as the aforementioned approaches have been attempted in industry, further application of on-line oil monitoring has been severely constrained. A coupling relationship between lubricant properties and wear performance of machine is determined in laboratory analysis [10]. However, the relationship is complex and mostly declared based on experiences, which makes a limitation on real time analysis with computer [11]. The problem in current on-line lubricating oil monitoring can be 


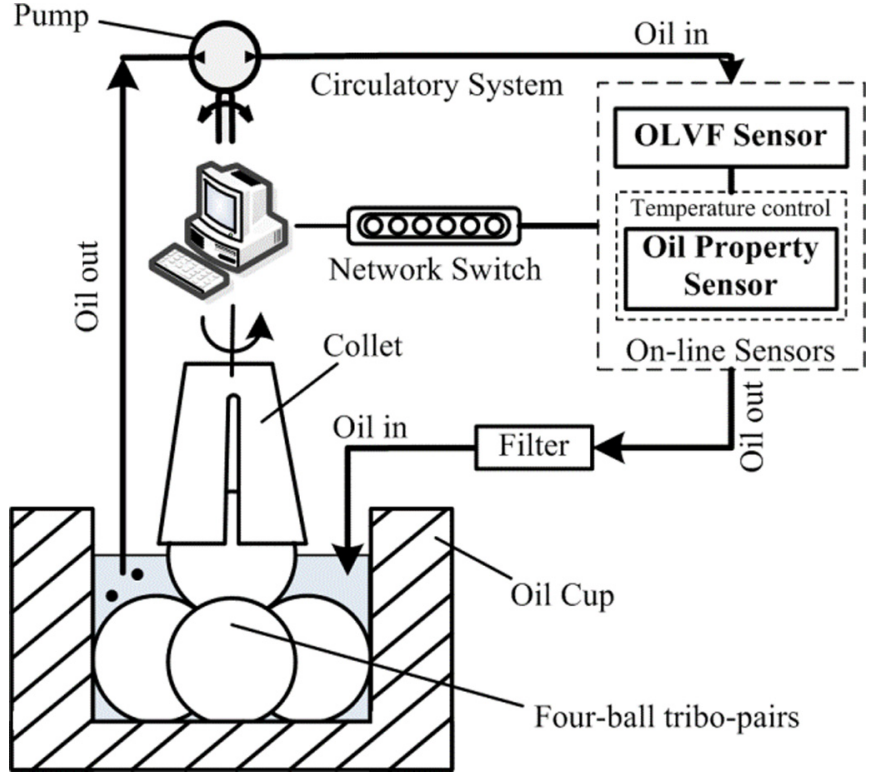

Fig. 1. Schematic diagram of on-line monitoring system.

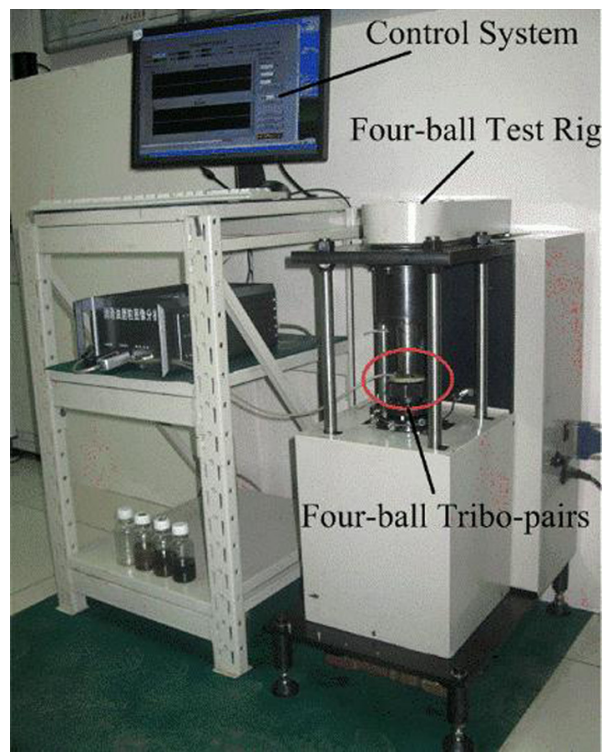

Fig. 2. Four-ball test rig.

generalized as: (1) numerous as the methods have been proposed to describe the condition of lubricating oil, sensors can only provide some physical value, while the mapping relationship between the value and real-time lubricant conditions is undetermined, which makes on-line application difficult to realized; (2) the deterioration of lubricating oil should be analyzed as a dynamical process, instead of sampling and probed in some time points; and (3) studies on lubricating oil monitoring have been confined in wear debris analysis, the degradation mechanism of lubricating oil remains indistinct in principle.

In order to overcome the current limitations in on-line monitoring on lubricating oil, an on-line lubricating oil monitoring system is constructed in this paper. Specifically,

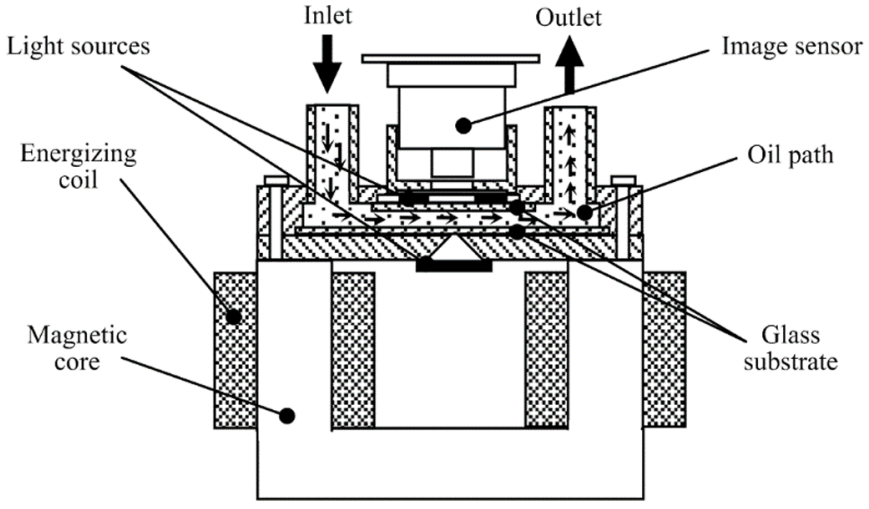

Fig. 3. Principle of OLVF sensor $[12,14]$.

the variation laws of lubricating oil deterioration characterized by viscosity, permittivity and wear characteristics are investigated to track the deterioration of lubricating oil. Furthermore, the results from on-line monitoring are examined with off-line analysis to verify the accuracy of on-line data.

\section{Experiment setup}

In this study, a four-ball tester is adopted in order to obtain service behaviors of lubricating oil and wear conditions of tribo-pairs under an operating machine. Real-time data of lubricating oil are required to interpret the variation laws of oil deterioration, where an on-line monitoring system consisted of oil property sensor and a wear debris sensor (OLVF sensor [12]) are employed. With the monitoring system, the viscosity and permittivity of lubricating oil and wear characteristics, which can reveal oil aging process, are investigated.

The principle of the tests is illustrated in Figure 1, including a four-ball tester and an on-line monitoring system, which mainly consists of on-line sensors (OLVF sensor and oil property sensor), an oil circulatory system and a temperature control system.

The four-ball tester was regarded as an operating machine to simulate running conditions and accelerate aging process of lubricating oil (Fig. 2). Working conditions can be artificially set and automatically realized by its control system at the beginning of the tests.

The OLVF sensor (Fig. 3) is the on-line visual ferrograph sensor [12-14], which is based on image technology. By processing the pictures, the size, distribution and concentration of wear debris can be obtained for the purpose of distinguishing wear conditions of the machine. The oil property sensor is a fluid property sensor, which is based on quartz crystal resonant characteristics to monitor the viscosity, permittivity and temperature of a fluid simultaneously.

The oil circulatory system (Fig. 4) made the oil circulate through the testing system. The pump helped the oil pass by the copper pipes through the sensors from the oil cup constantly to obtain real-time data of oil properties and wear conditions, then return back into the cup. There was no oil wasted in this circulatory system. 


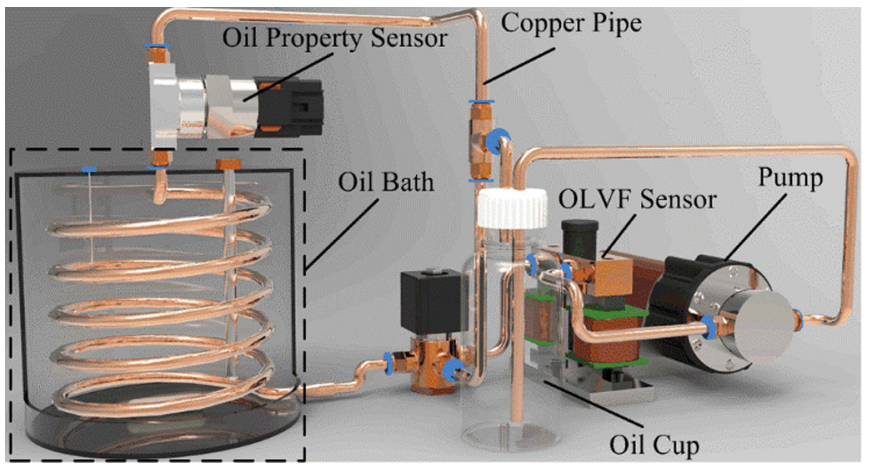

Fig. 4. Oil circulatory system.

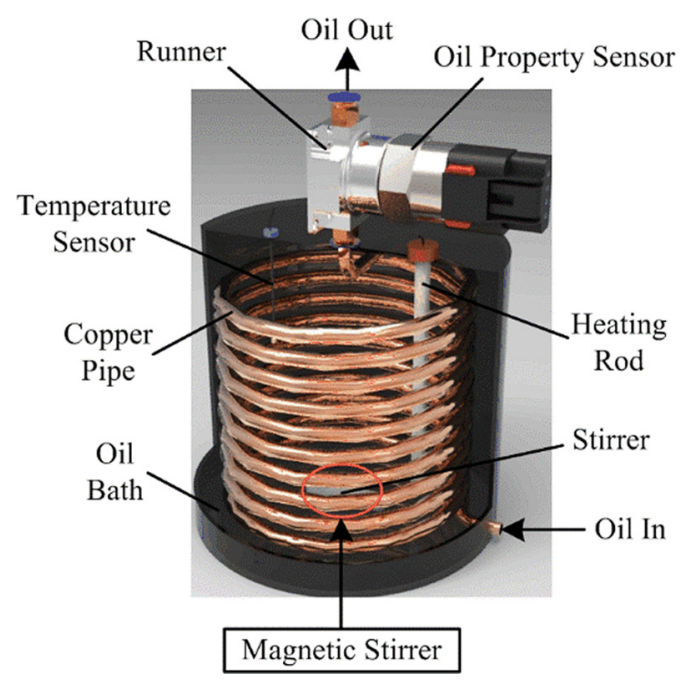

Fig. 5. Temperature control system.

Table 1. Working conditions for the test.

\begin{tabular}{llllllr}
\hline Section no. & $\begin{array}{l}\text { Load } \\
(\mathrm{N})\end{array}$ & $\begin{array}{l}\text { Rotated rate } \\
(\mathrm{rpm})\end{array}$ & $\begin{array}{l}\text { Contact stress } \\
(\mathrm{GPa})\end{array}$ & $\begin{array}{l}\text { Line velocity } \\
(\mathrm{m} / \mathrm{s})\end{array}$ & $\begin{array}{l}\text { Time } \\
(\mathrm{h})\end{array}$ & $\begin{array}{l}\text { Downtime duration } \\
(\mathrm{h})\end{array}$ \\
\hline 1 & 1500 & 1000 & 2.5 & 0.38 & 6 & \\
2 & 1500 & 1000 & 2.5 & 0.38 & 6 & 4 \\
3 & 2000 & 1000 & 2.75 & 0.38 & 3.5 & 12 \\
4 & 2000 & 1000 & 2.75 & 0.38 & 4 & 1 \\
5 & 2000 & 1500 & 2.75 & 0.57 & 1 & 8 \\
\hline
\end{tabular}

The temperature control system (Fig. 5) was adopted to monitor oil properties, such as viscosity and permittivity, under a certain temperature, on account that the properties strictly have close relationship with temperatures. We use a heating rod to keep the oil bath fixed to a required temperature, where the temperature sensor is supplied to give feedbacks to the controller. By doing this, the viscosity, permittivity and temperature of lubricating oil are measured by the oil property sensor. Afterwards, the variation of oil properties under a fixed temperature in an aging process can be studied.

To simulate and accelerate oil degradation, a four-ball test composed with varied loads and speeds was carried out. By monitoring the variations of oil properties and wear conditions, the aging process was recorded. Details of varied conditions are shown in Table 1 . The test was stopped and restarted when working conditions were changed. The waiting time for the intervals lasted a few hours to make sure each test starts with room temperature.

\section{Results and discussions}

\subsection{On-line data analyses}

The total testing time is $1230 \mathrm{~min}$, and the testing temperature of oil property sensor is fixed to $50{ }^{\circ} \mathrm{C}$. The test is divided into five sections presented in Table 1 , and the real-time data of wear characteristics, permittivity and viscosity of lubricating oil obtained by OLVF sensor and oil property sensor are shown in Figures 6-9. Some results can be found as follows.

\subsubsection{On-line wear monitoring results}

OLVF sensor obtained wear debris images (Fig. 6) in every 4 min to record wear conditions of the tribo-pairs in the four-ball test. As we can conclude from the images, at the beginning of the test, a lot of particles are produced, which can attribute to make the rough peak of the friction surfaces smooth, so called run-in period; after running in, few particles are detected, which means the friction pairs are working at their best conditions, as named normal period; at the end of the test, much more particles are monitored accounting for severe wear, named severe period.

In order to visually describe the state of wear, IPCA (index of particle coverage area, representing the concentration of wear particles and the wear condition variations) are proposed [15], and the variation of IPCA during the whole test is shown in Figure 7 . The curve illustrates the typical three stages of wear conditions, including run-in period, normal period, and severe period, which agree with the "bathtub curve".

At every stop and start points, the contact point of the tribo-pairs is different from the prior point due to the rotation of the upper ball. Therefore, a short run-in stage 


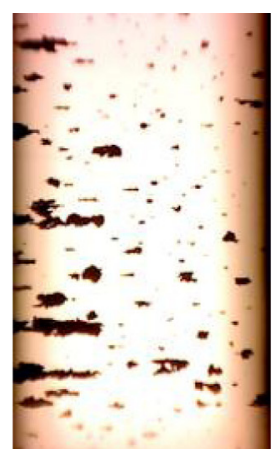

(a) $10 \mathrm{~min}$

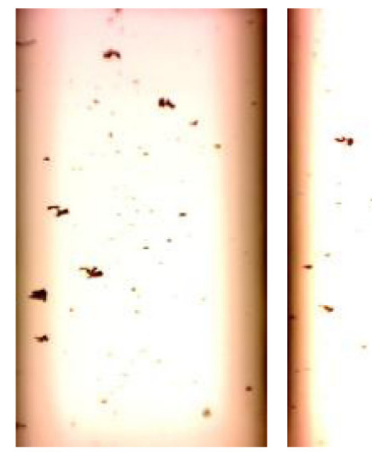

(e) $450 \mathrm{~min}$

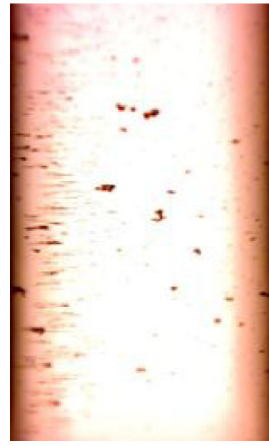

(i) $1100 \mathrm{~min}$

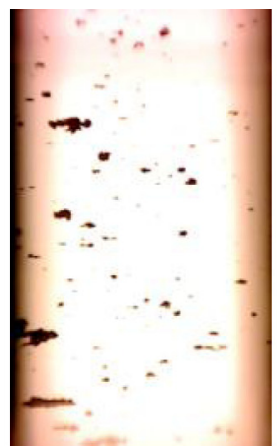

(b) $50 \mathrm{~min}$

(f) $650 \mathrm{~min}$

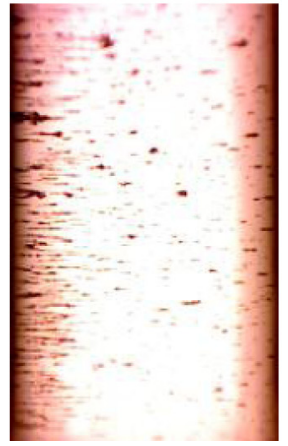

(j) $1150 \mathrm{~min}$

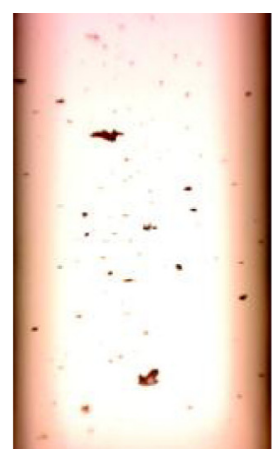

(c) $150 \mathrm{~min}$

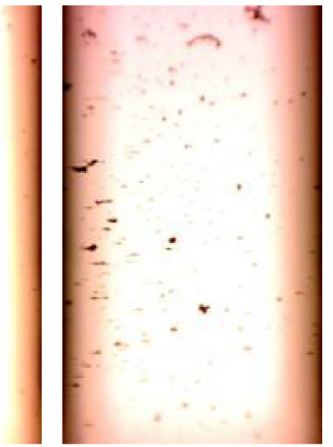

(g) $800 \mathrm{~min}$

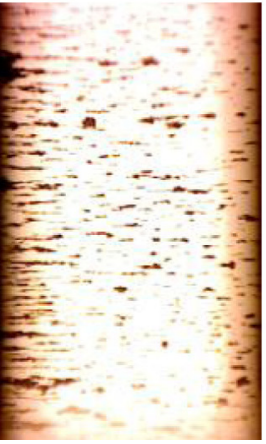

(k) 1200min

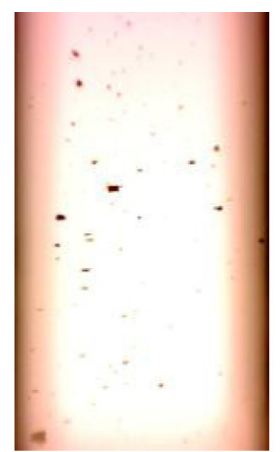

(d) $250 \mathrm{~min}$

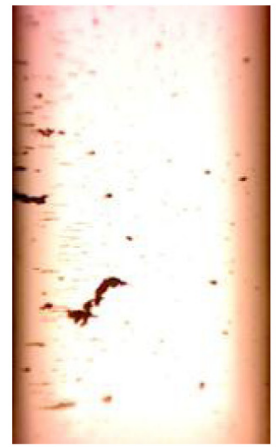

(h) $1000 \mathrm{~min}$

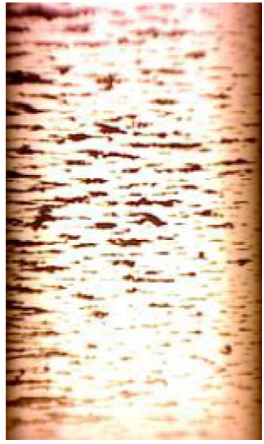

(1) $1250 \mathrm{~min}$

Fig. 6. On-line wear debris images obtained by OLVF sensor.

occurs at the beginning of each section, which we can obtain from the curve that the values of IPCA are larger at every start point. Moreover, the severe stage shows greater wear than the run-in one. In addition, the average of IPCA in sections 1 and 2 is 0.0018 and the average of IPCA in section 3 is 0.0088 , which shows the trend that the heavier the loads, the greater the wear; similarly, the average of IPCA in section 4 is 0.0110 and the average of IPCA in section 5 is 0.0484 , which shows the trend that the faster the speeds, the heavier the wear.

\subsubsection{On-line oil properties' results}

The permittivity and viscosity of lubricating oil under a certain temperature are monitored by oil property sensor. The variation curve of permittivity (Fig. 8) shows a slight reduction at the first section; remains almost a stable condition at sections $2-4$; then sharply increases at the last section.

At the beginning of the operation, the polar additives in lubricating oil, such as antioxidant, anti-wear additives and so forth, react chemically, which lead to the losses of additives and finally causes the drops of permittivity. Nevertheless, the oxidation reaction of lubricating oil produces acidic oxides, which leads to the rise to permittivity. Besides, the increase of wear debris can also lead to the increase of the permittivity of lubricating oil, presented in section 5 .

The variation curve of the viscosity of lubricating oil (Fig. 9) illustrates an uptrend in the full test. At every stop and start point, the values of viscosity have a sharply drop. With the attribution of the additive of viscosity index 


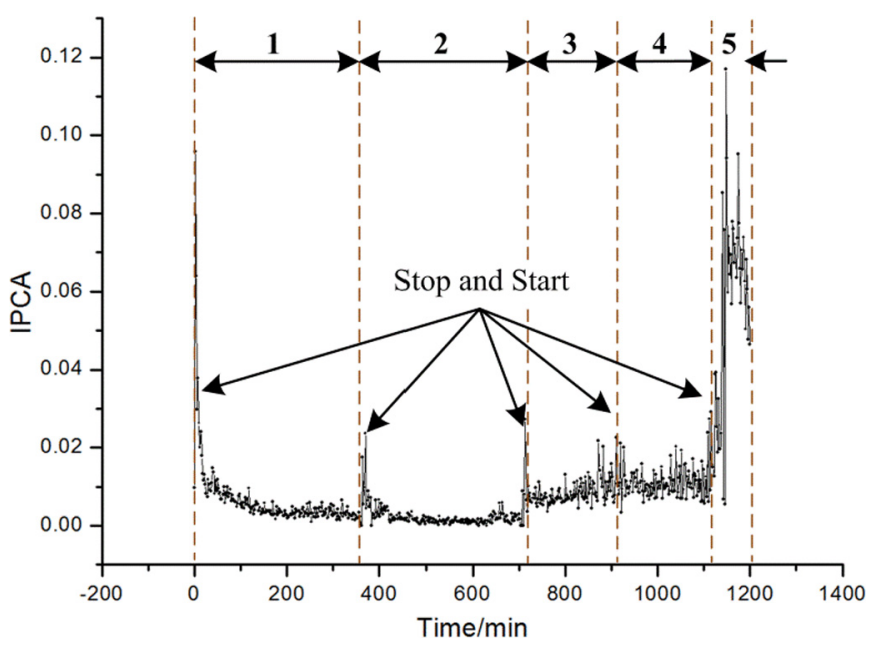

Fig. 7. Variation of IPCA over testing time.

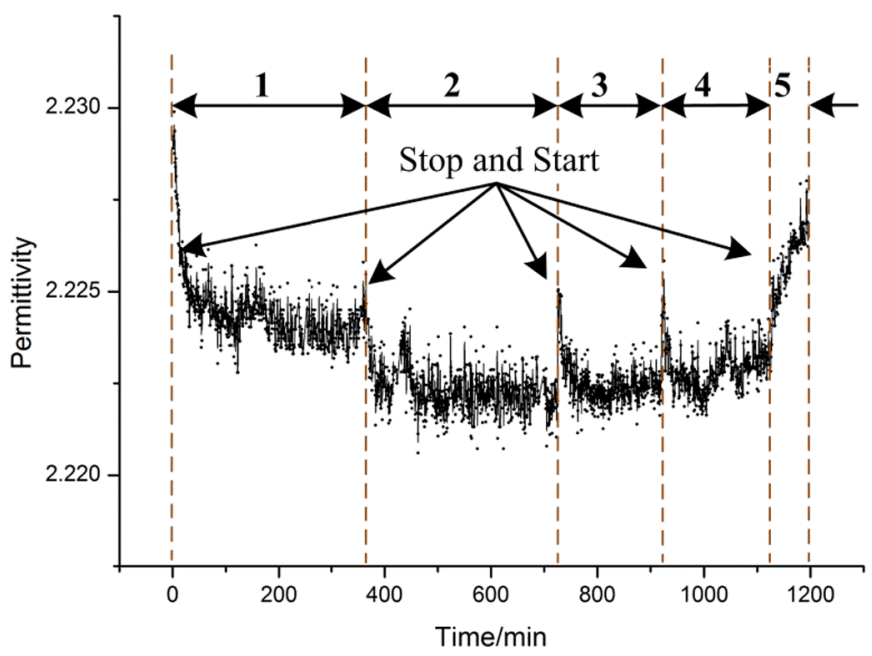

Fig. 8. Variation of permittivity over testing time.

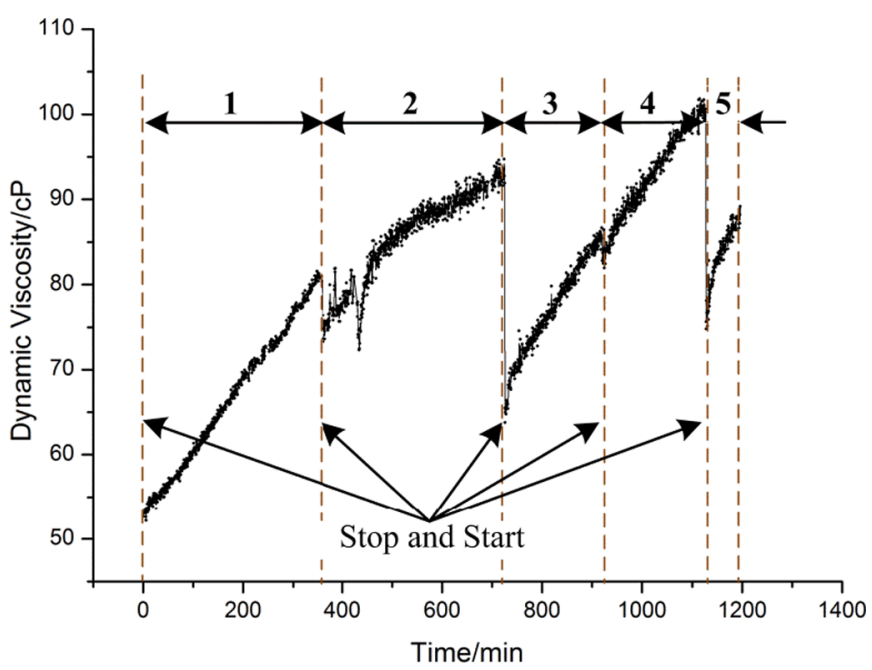

Fig. 9. Variation of viscosity over testing time.

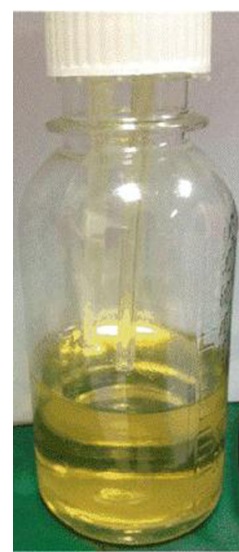

New Oil

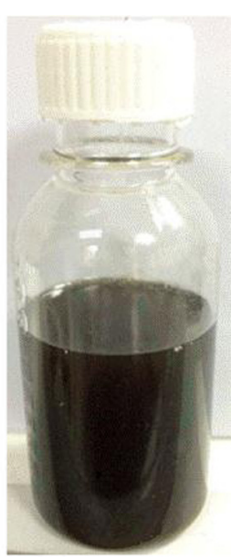

Used Oil
Fig. 10. Oil samples of the new oil (left) and the used oil (right).

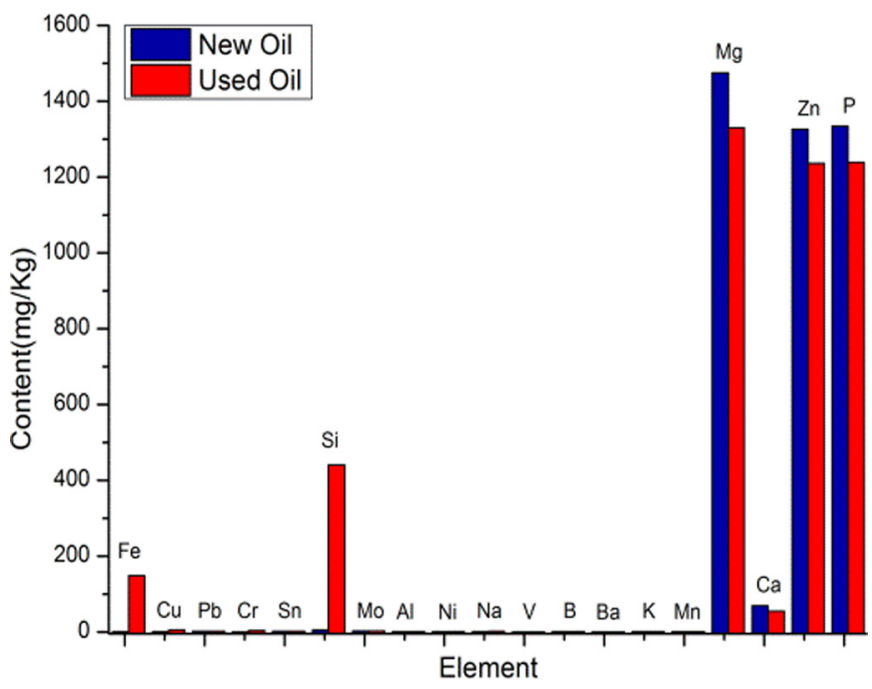

Fig. 11. Element composition analysis between the new oil and used oil.

improver in the synthetic oil, the behaviors of the viscosity of lubricating oil on working conditions are different with that on non-working conditions $[4,16]$. In addition, the rate of viscosity variation is much bigger under severe working conditions (obtained from the slopes of the lines at sections 2 and 3 ), which means that the rate of viscosity variation can reflect the severe conditions of tribo-pairs.

\subsection{Validation results with off-line analyses}

Off-line data analysis is adopted with the purpose of verifying the accuracy of the on-line data obtained by online sensors. Therefore, element composition analyses and filter analyses are employed. New oil and the used oil (Fig. 10) are required to off-line analysis.

\subsubsection{Elemental analyses}

Element composition analysis (ASTM D6595-00) is used to compare the differences between new lubricating oil and the used one (Fig. 11) in the test, where the content of the elements in oil can be acquired. 

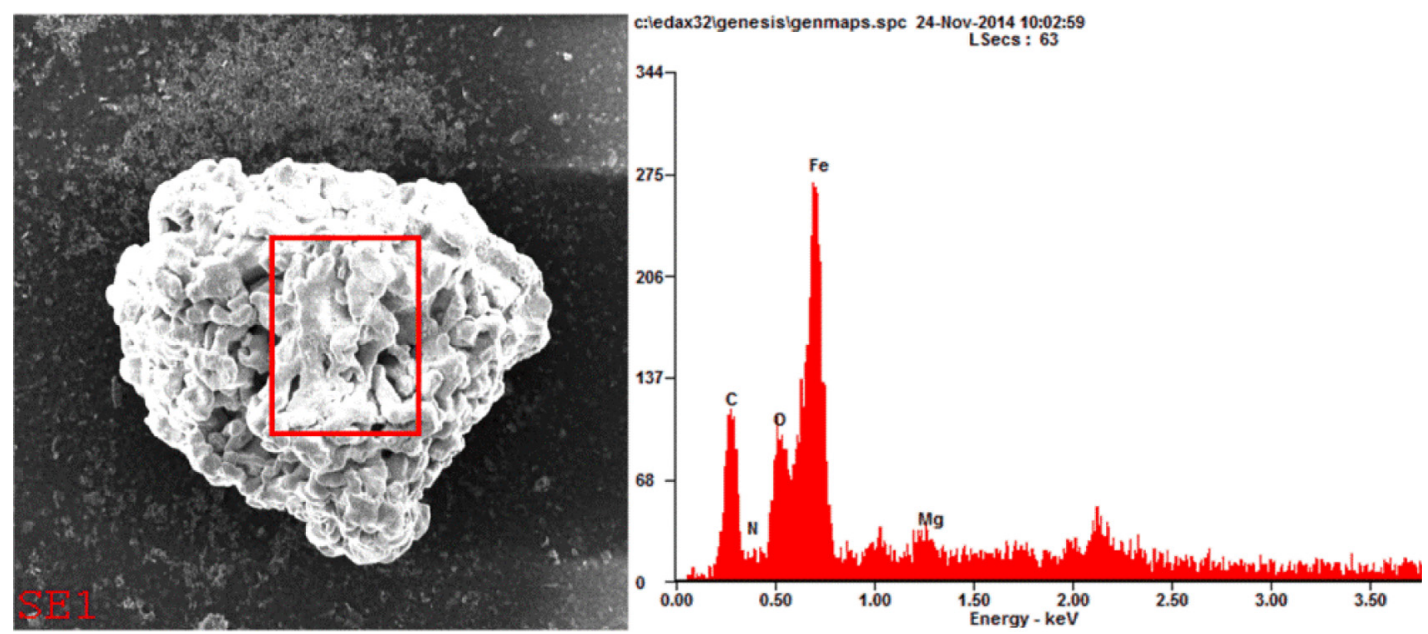

(a) Iron Oxides
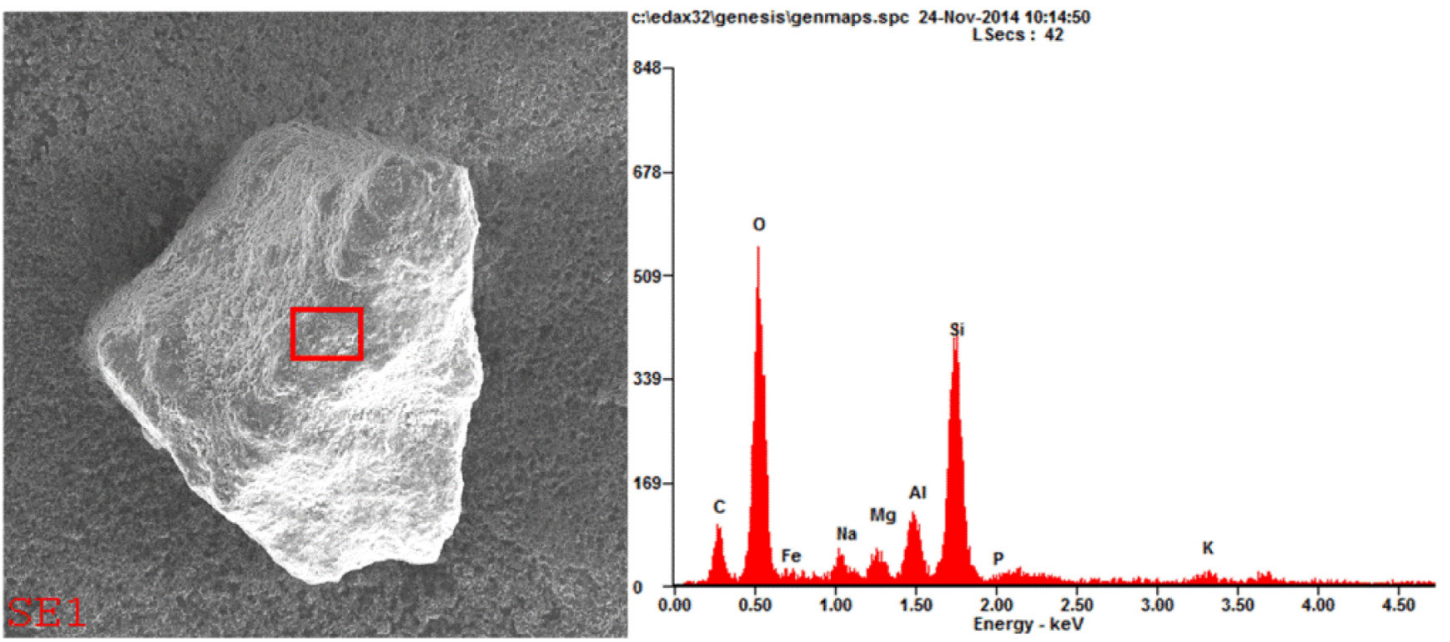

(b) Silicon Oxides
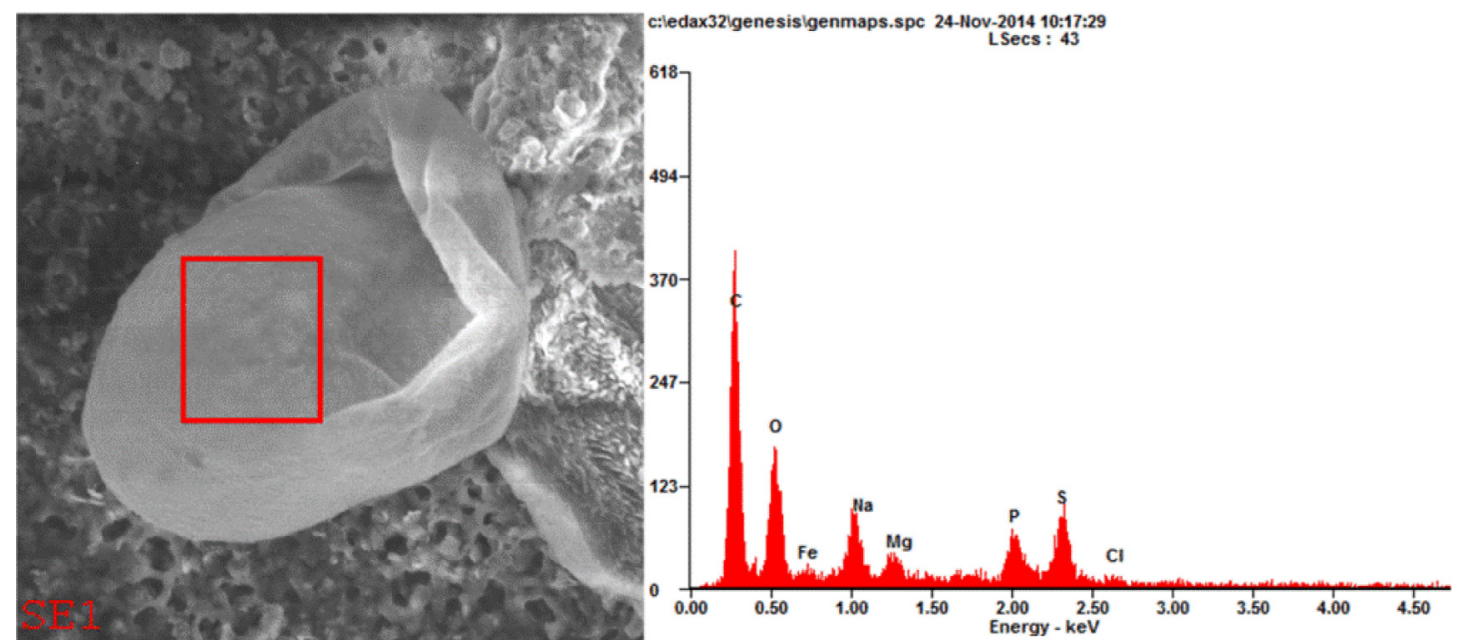

(c) Colloidal Substances

Fig. 12. Filter analysis for elemental composition. 
Table 2. On-line and off-line viscosities of lubricating oil.

\begin{tabular}{lll}
\hline Sample & On-line method $(\mathrm{cP})$ & Off-line method $(\mathrm{cP})$ \\
\hline New oil & 52.65 & 52.64 \\
Used oil & 89.18 & 51.59 \\
\hline
\end{tabular}

It can concluded that the main metal particle in the degradation process is iron $(\mathrm{Fe})$ caused by the wear of tribo-pairs, which can be monitored by OLVF sensor as well; the main non-metal particle is silicon $(\mathrm{Si})$ attributing to the dust in the air, which may lead to the acceleration of wear process, but cannot be detected in this on-line monitoring system; $\mathrm{Mg}$ and $\mathrm{Ca}$ represent the existence of detergent-dispersant additives, and $\mathrm{Zn}$ and $\mathrm{P}$ represent that there are anti-wear additives and anti-oxygen additives in the oil; on this account, the losses of these elements declare that the additives of lubricating oil have been consumed when the oil is served for the tribo-pairs under an operation machine, which explains the decrease of permittivity on on-line measurements as well.

Since the element $\mathrm{C}$ cannot be detected by element composition analysis, filter analysis is adopted, where field emission scanning electron microscopy (SEM SU-8010) is employed. We can see from filter membrane (Fig. 12) that there are a lot of black metal oxides (iron oxides) and dust particles (silicon oxides) deposits in the lubricating oil, as well as some small amount of colloidal substances (carbon or fibers).

\subsubsection{Viscosity analysis}

The comparison results between on-line viscosities and offline viscosities are presented in Table 2 . The results of new oil are the measurements of lubricating oil at the beginning of the test, and the results of used oil are the measurements of lubricating oil at the end of the test.

It can be found that after 1230 minutes' severe working, the off-line viscosity of lubricating oil remains almost unchanged, while the on-line viscosity increases a lot.

\section{Conclusion}

Lubricating oil deterioration on the four-ball tester, as well as wear conditions, can be detected by the developed online monitoring system in real-time. The deterioration process of lubricating oil and the variations of the above indexes (IPCA, permittivity and viscosity) can be concluded as follows:

- The deterioration process of lubricating oil tracked by on-line monitoring system is investigated. The three indexes, IPCA, permittivity and viscosity of lubricating oil, can record the aging process of lubricating oil, which has been verified by off-line analysis.

- IPCA represents the wear particle concentration in oil, and demonstrates three stages including run-in, normal wear and severe wear in the running process, which agrees with the typical "Bathtub Curve". By changing working conditions, we can see that this kind of monitoring parameters is sensitive to recognize different working conditions, owing to heavy loads leading to the severe wear in this test.

- The variation of permittivity illustrates the changes of the polar elements in oil, such as the losses of additives and the acidic productions of oxidation, which are verified by off-line oil analyses.

- The variation of viscosity increased gradually at each section, which indicates the lubricating conditions of the oil on its serving time. The rate of the variation indirectly represents different working conditions of the tribo-pairs. Moreover, there are different laws between the results of on-line monitoring and off-line measurements, which attribute to the additives of viscosity index improvers that work on the dynamic process to help prevent viscosity decrease caused by high temperatures.

The financial supports for the present research were provided by the National Science Foundation of China (Grant Nos. 51675403 and 51275381) and the support of K.C. Wong Education Foundation. The authors would also like to acknowledge all the members of the Tribology Research Group in the School of Mechanical \& Manufacturing Engineering for very helpful discussions. Additionally, the work was originally accepted for and presented at MITC2015.

\section{References}

[1] P.O. Vähäoja, H.V.S. Pikkarainen, Trends in industrial oil analysis - a review, Int. J. Cond. Monit. 1 (2011) 4-10

[2] R.M. Mortier, M.F. Fox, S.T. Orszulik, Chemistry and technology of lubricants, 3rd edn., Springer, UK, 2010

[3] A. Mujahid, F.L. Dickert, Monitoring automotive oil degradation: analytical tools and onboard sensing technologies, Anal. Bioanal. Chem. 404 (2012) 1197-1209

[4] H. Singh, S. Swaroop, Oxidation behavior of base oils and their constituting hydrocarbon types, Prep. ACS Div. Petrol. Chem. 42 (1997) 218

[5] L. Guan, X.L. Feng, G. Xiong, J.A. Xie, Application of dielectric spectroscopy for engine lubricating oil degradation monitoring, Sens. Actuators A: Phys. 168 (2011) 22-29

[6] D.C. Schalcosky, C.S. Byington, Advances in real time oil analysis, Pract. Oil Anal. Mag. 11 (2000) 28-34

[7] S. Kumar, P.S. Mukherjee, N.M. Mishra, Online condition monitoring of engine oil, Ind. Lubric. Tribol. 57 (2005) 260-267

[8] L.A.R. Baptista, L.A.V. Pinto, C.R.P. Belchior, Condition monitoring of engines by lubricating oil analysis, SAE Technical Paper, 1999-01-3001, 1999

[9] T. Cargol, An overview of online oil monitoring technologies, Proceedings of the Fourth Annual Weidmann-ACTI Technical Conference, San Antonio, 2005

[10] A. Toms, L. Toms, Oil analysis and condition monitoring, in: Chemistry \& technology of lubricants, 2010

[11] G.E. Newell, Oil analysis cost-effective machine condition monitoring technique, Ind. Lubric. Tribol. 51 (1948) 119-124

[12] T.H. Wu, J.H. Mao, J.T. Wang et al., A new on-line visual ferrograph, Tribol. Trans. 52 (2009) 623-631 
[13] T. Wu, W. Wang, J. Wu et al., Improvement on on-line ferrograph image identification, Chin. J. Mech. Eng. 23 (2010) 1

[14] T.H. Wu, H.K. Wu, Y. Du et al., Progress and trend of sensor technology for on-line oil monitoring, Sci. China Technol. Sci. 56 (2013) 2914-2926
[15] T.H. Wu, J.Q. Wang, J.Y. Wu et al., Wear characterization by an on-line ferrograph image, Proc. Inst. Mech. Eng. J.: J. Eng. Tribol. 225 (2011) 23-34

[16] A. Agoston, C. Ötsch, B. Jakoby, Viscosity sensors for engine oil condition monitoring - application and interpretation of results, Sens. Actuators A: Phys. 121 (2005) 327-332

Cite this article as: Y. Du, T. Wu, L.X. Wang, R.J. Gong, Investigation on on-line monitoring method for lubricating oil deterioration, Mechanics \& Industry 18, 402 (2017) 